Đuro Šušnjić, Beograd

\title{
TEORIJSKO I ISTORIJSKO: RAZUMEVANJE RELIGIOZNE VERE I NEVERE
}

Tri su pitanja kojima mogu koliko-toliko da obuhvatim i shvatim široko duhovno polje Ivana Cvitkovića: šta jeste religija, odnos religije i religijske ideologije i dijalog i tolerancija među religijama. Svakom pitanju su potrebna druga dva, pa se ne može zameniti jedno, a da se ne promene ostala. U stvari, nema toga elementa u strukturi religije o kome naš i vaš Ivan nije rekao svoju reč. Tako on, između ostalog, raspravlja o odnosu religije i nacije, religije i politike, religije i nasilja, crkve i države, religije i društvene promene, religije i medija, religije i sekularizacije, religije i izbora, religije i porodice itd.

\section{Pojam religije}

Ponekad moramo neku reč da izvadimo iz jezika, kako bismo je dali na čišćenje - a zatim možemo opet da je uvedemo u saobraćaj.

Ludvig Vitgenštajn

Pre odgovora na pitanje šta jeste religija Ivan Cvitković daje nekoliko napomena ili opomena, čiji je smisao da se raščiste srodni ili veoma slični pojmovi kao što su natprirodno, sveto, profano... Ako bismo na samom početku znali šta je religija, onda bi bilo suvišno svako iskustveno istraživanje religije. Idealne definicije moguće su u logici, matematici i geometriji, ali ne i u naukama o čoveku - da desna strana definicije bude jednaka levoj.

Pitanje šta je religija jeste opšte pitanje, koje se mora raspraviti pre svih posebnih, jer sve ljudske zajednice imaju religiju, ali nemaju sve istu religiju. Zato je nužno da se razlikuje religija kao opšti pojam od posebnih oblika religiozne vere. Opšti pojam religije određuje opšta metodologija, logika i teorija saznanja, dok se svaka posebna religija uglavnom istražuje pomoću neke specifične teorije i empirijskih metoda i tehnika. Ako odgovorimo na pitanje šta jeste religija, onda smo u isto vreme rekli šta ona nije - imamo kriterijum za razlikovanje religijskih i nereligijskih ideja, verovanja i vrednosti. Ivan Cvit- 
ković $(1999: 19,28)$ to kaže ovako: "Moramo utvrditi neke zajedničke kriterije, elemente po kojima ćemo nešto ocjenjivati kao religiju... Neko određenje religije treba dati, polazeći od kriterija koji su zajednički za razne religije."

Savremena nauka je umorna od silne tehnike koja se gotovo osamostalila, jer je izgubila vezu sa teorijom i filozofijom nauke. Nauka ima previše tehnike, a premalo duše. Ona hoće sve da izmeri, jer smatra da je meriti isto što i znati. "Mislioci u brojevima" obožavaju tehniku i nalaze zadovoljstvo u tom radu. Tako se desilo da smo iz doba visokih ideja i nerazvijene tehnike ušli u doba usavršene tehnike i prizemnih ideja i tzv. teorija srednjeg obima, iza kojih stoji shvatanje čoveka osrednjeg duhovnog stanja. Nekada je teorijski duh bio nadmoćan praktičnom, tako da se nije postavljalo pitanje proveravanja teorija na činjenicama. Danas je obrnuto: veoma su razvijene tehnike prikupljanja, opisivanja i merenja činjenica, ali uz zanemarivanje ili čak odsustvo teorije. Albert Ajnštajn je zaključio: "Teorija je kad se sve zna, a ništa ne funkcionira, za razliku od prakse, kad sve funkcionira, a nitko ne zna zašto." Ivan Cvitković (2016: 17-18) dodaje: "Može se reći da je sociologija devedesetih godina napustila velika teorijska pitanja klasične sociologije u korist proliferacije anketa malog dometa pomoću upitnika ili sudjelujućeg promatranja. One su postepeno zadobile status kanonskog modela."

Ima reči (i pojmova) koje na prvi pogled izgledaju jasne i razgovetne, sve dok ne razmišljamo o njima, a čim to učinimo, one postaju nejasne i zbrkane - neprijatne duhu i izrazu. Dakle, jedna reč, časna i verna svojoj ulozi u običnom, zdravorazumskom iskustvu, postaje nejasna, nedostojna i izdajnička u funkciji nekog višeg i složenijeg značenja. "Kad se tako najpoznatija stvar ukaže kao dubinski nepoznata, bez značenja" (Valeri 2010: 137), “Jezik je, možda, uistinu pretrpeo nervni slom, ali, kao što možemo pretpostaviti, to nije ništa fatalno. On će, verovatno, nastaviti da pokušava da pređe sopstvene granice i da zađe u zabranjeno carstvo neizrecivog" (Kolakovski 1992: 42; obavezno v. i: Cvitković 2005).

Ivan Cvitković, svestan jezičkih zamki, teži da se svestranije i dublje raspita o pojmu religije. Tako on pokazuje i dokazuje da uobičajena definicija religije kao verovanja u boga nije prihvatljiva, jer ima religija i bez boga (šire u Cvitković 1996: 25). Na sličan način on kritikuje i određenje religije kao verovanje u natprirodno ili neprirodno, jer su to pojmovi koji pripadaju zapadnom idejnom sistemu, a kod drugih naroda takav pojam ne mora nužno da postoji (šire u Hamilton 2003: 78-79, 362). Ni pojam sveto ne može da izdrži kritiku, premda je širi od pojma natprirodno, jer sve može biti sveto, ali ne mora biti natprirodno (na primer sveta krava, sveti miš itd.). Ako sve može da bude sveto, to jest ako se ukida razlika između svetog i svetovnog, 
onda je svejedno šta će se uzeti za predmet obožavanja: kamen, drvo, voda, zemlja, vatra, sunce, životinja, mrtvi predak! Jer se drži svetom ona tajnovita i apsolutna moć koja prebiva u svakoj pojavi, a ne sama pojava.

U svojim brojnim radovima Ivan Cvitković često upozorava i na razliku između crkvenosti i religioznosti. Broj onih koji veruju svuda je mnogo veći od broja onih koji vrše verske obrede u crkvi. Prema tome, religioznost je širi pojam od crkvenosti, jer ima religioznih i izvan crkve. Crkva nije jedino mesto susreta ljudi i njihovih bogova: ne može se verski odnos svesti na pripadanje crkvi! Pojava osobne ili lične vere dokaz je da vernikov izbor nije okončan pripadanjem verskoj ustanovi. Ulrih Bek reče: "Danas je moguće izabrati i samog boga." Da crkva zadovoljava sve potrebe vernika, ne bi se oni tako udaljavali od nje, ali, kako reče jedan vernik, bolje sa bogom bez crkve nego sa crkvom bez boga. Postoji divna izreka: "Živim u jatu, ali lovim sam." Vera je često stvar ličnog iskustva koje je neizrecivo i neprepoznatljivo u zvanično predviđenim oblicima (na primer u učenim teološkim raspravama, crkvenim obredima itd.).

Ima vernika koji u zvaničnoj veri, obredu i organizaciji verskog života ne nalaze ispunjenje svojih verskih potreba. To su, na primer, mistici, monasi, askete i jeretici, usamljeni ljudski glasovi, koji ne podnose moćne sile obezličenja. I oni veruju u boga i veruju bogu, ali ne mare za uhodane i okamenjene oblike vere, kad se otvorena misao zamrzne u dogmu, kolektivni obred potisne i zameni lično iskustvo, vrednost se pretvori u normu, ličnost u ulogu, ljubav u obavezu. Uostalom pojam crkva je preuzak i ne pokriva lična iskustva, a i ne postoji u nekim religijama (kao, na primer, u islamu) (šire u Cvitković 2016: 11).

Na kraju, naš poznati i priznati sociolog religije Ivan Cvitković pravi razliku između pojmova religije i vere. Vera se izražava u različitim oblicima, kao na primer: vera u sebe, vera u vođu, vera u naciju, vera u klasu, vera u nauku, vera u napredak, vera u slučajnost... Nijedan od ovih oblika vere nema bitne veze sa religioznom verom - to je vera u nešto mistično $i$ apsolutno. Otuda se pojmovi vere i religije ne mogu izjednačiti ni po obimu ni po sadržaju, jer je vera, kako znamo, širi pojam od religiozne vere.

Kad god bi neki filozof odlučio da napiše istoriju filozofije, morao je da ima merilo za razlikovanje filozofskih ideja od svih drugih vrsta ideja. To merilo jeste njegova definicija filozofije: ona mu kaže koje ideje treba da uvrsti u svoju istoriju, a koje mora da izostavi, jer u nju ne spadaju. Isto tako, ako neko odluči da napiše istoriju jedne religije ili religija, onda i on mora imati merilo za prepoznavanje religijskih ideja, verovanja i radnji od svih drugih oblika mišljenja, verovanja i ponašanja. To merilo je njegova definicija reli- 
gije, koja ga vodi kroz složeni, raznovrsni i višeznačni svet duha: definicija upućuje šta da uključi, a šta da isključi iz svoje istorije religije ili religija. Merilo jasno govori šta religija jeste, a u isto vreme šta ona nije: razgraničava religiju od drugih oblika ideja, verovanja i delanja. "Ali, valja, ipak, definirati po čemu, po kojim kriterijumima razlikujemo nešto kao religijsko. Neko određenje religije treba dati, polazeći od kriterija koji su zajednički za razne religije" (Cvitković 1996: 30). ${ }^{1}$

Već je Erazmo Roterdamski primetio da "suština stvari zavisi samo od tačke gledišta". Jedan drugi pisac nadovezao se rečima: "Definicija pripada onom ko definiše, a ne onom što se definiše" (Flenegal 2005: 171). Imajući u vidu da spoznajni subjekt definiše dati objekt u skladu ne samo sa svojim saznajnim nego i vansaznajnim potrebama, interesima i željama, naš sociolog religije u svojim radovima ne propušta da istakne ne samo strukturalne nego i funkcionalne elemente religije. Ako se ne varam, i on vidi religiju kao osoben način života (a ne samo mišljenja, kao što su filozofija i nauka), koji se opisuje u njenom učenju (racionalna teologija), doživljava u iskustvu, ostvaruje ili ospoljuje u obredima, izražava u simbolima, ogleda u vrednostima, propisuje u normama (izvedenim iz vrednosti), oživotvoruje u zajednici vernika, kristalizuje u ustanovama (crkva, hram), otelovljuje u harizmatskim ličnostima, oseća na svetim mestima i u sveto vreme.

Ivan Cvitković zna da nije dovoljno prepoznati ili otkriti elemente, odnosno delove religije, već da je neophodno steći uvid u međusobni odnos tih delova u različitim religijskim sistemima (budizmu, hrišćanstvu, islamu itd.). Dve religije mogu imati posve iste sastavne delove, ali različitu strukturu, jer su ovi delovi međusobno povezani na dva različita načina. Tako struktura označava delove religije (to jest iz čega se ona sastoji), ali i međusobni odnos tih delova u njoj. Uočiti središnji značaj i značenje nekog elementa ili dela u jednoj religiji u isto vreme znači uočiti onaj element i delove koji su manje značajni i moćni, ili čak teže da nestanu iz nje, odnosno iz života vernika.

Tako je za jednu religiju od prevashodne važnosti njeno učenje (dogmatski tip religiozne vere), za drugu su to obredi (ritualistički tip vere), za treću iskustvo (emocionalno-mistični tip vere), za četvrtu ustanova (institucionalizovane religije), za petu verske vrednosti (etičke religije), za šestu norme (religije zakona), za sedmu ličnost (harizmatski tip vere) itd. Vidimo da jedan element, odnosno deo, zauzima središnje mesto u celini, dok se svi ostali raspoređuju oko ovog žarišta vere, podupirući jedan drugog u proizvodnji značenja i zna-

\footnotetext{
${ }^{1} \mathrm{Na}$ drugom mestu, verovatno pod uticajem postmoderne, Ivan kao da odstupa od ove definicije: "Nema univerzalne definicije religije koja bi važila za sve religije, i za sva vremena" (Cvitković 2016: 8, 12).
} 
čaja. "U nerazvijenim društvima obredna strana religije je razvijenija (Boga najviše mole u nesreći). U razvijenim društvima više stavljaju naglasak na intelektualnu nego na obrednu (folklornu) stranu religije" (Cvitković 1999: 23).

Red je da se još nešto kaže o vrednosno-normativnim sistemu tako osobenom za hrišćansku i muslimansku veru. Ako je čovek po prirodi zlo biće, onda nema nikakvog razloga da se zgražamo nad njegovim nedelima, jer tu krivice i greha nema. Ali sama činjenica da se zgrozimo nad nečijim zločinom govori i o svetloj strani ljudske prirode. Sledi da čovek nije samo loš nego i dobar: u njemu se sadrže obe mogućnosti, a koja će preovladati, to često zavisi od okolnosti. Hrišćanska vera pored boga poznaje i đavola: tu je izvor ne samo hrišćanskog optimizma nego i pesimizma.

Moralni i pravni sistemi temelje se na pesimističkom shvatanju ljudske prirode. Ako bi čovek po svojoj prirodi bio dobar, onda bi bili suvišni svi tabui, verske, običajne, moralne i pravne norme. Čim one postoje, znači da nešto nije u redu sa našom prirodom. Neko, ne znam više ko, dobro reče: "Da su svi ljudi anđeli, nijedna vlada ne bi bila potrebna.” Antropološki pesimizam priziva autoritarni način vladanja čovekom: njegovi neobuzdani nagoni (osobito libido dominandi) stoje kao stalna pretnja zdravom društvu, koje sebe mora da obezbedi normama, pravilima i ustanovama. Svaki sistem vrednosti, normi i pravila stoji nasuprot nekom zlu. Ako se sistem vrednosti i normi raspao ili ako ga nema, zlo igra po svojim pravilima. Jedan život ne može se smatrati vrednim ako se iscrpe u tome da se laže, krade, pljačka, ubija. Vrednim se smatra onaj život u kome se ostvaruju vrhovne vrednosti ljubavi, pravde i slobode. Pojam vrednosti čovek koristi da bi razumeo sebe i osmislio svoj put u životu. Jer on može steći sve, a izgubiti sebe.

Svaka mreža društvenih ustanova može se razumeti kao prevođenje misli, verovanja i vrednosti u stvarne norme, pravila i uloge, to jest u društvene odnose, pri čemu je uvek na delu sakaćenje: duhovno bogatstvo sadržano u mislima, verovanjima i vrednostima ostvaruje se samo delimično. Ali, što se gubi na širini, dubini i spontanosti, dobija se na sigurnosti, stabilnosti i predvidljivosti. Zaključak je jasan: svaka ideja, verovanje i vrednost teži da se ustanovi, ali čim postane ustanova, gubi na svojoj istini, svetosti i lepoti. Gubitak se može otčitati u razlici između ideje i ideologije, harizmatske ličnosti i tirana, pokreta i poretka. U Fenomenologiji duha Hegel je tačno zapazio: "Na onome u čemu je duh zadovoljan može se odmeriti veličina njegovog gubitka." Norme, pravila i ustanove jesu ono preko čega se pojavljuju vrednosti i viša značenja. Ono najbolje u svakom društvu jesu vrednosti i vrhovna značenja koja nisu dospela da se ostvare, da se ustanove, i koja i dalje ostaju kao putokazi za rad društva na samome sebi. 
Misao može biti delatna samo ako je ograničena. Neograničena ne može dobiti vremenske i prostorne oblike. Delanje postoji samo kao ograničeno delanje, jer ako ne bi bilo ograničeno, ne bi se ticalo čoveka, nego boga. Ograničenost u delanju postaje udes, kob, sudbina, i čovek jedino izmiče udesu u mišljenju bez granica, mašti: ovde je on biće obdareno slobodom, dok je u delanju nužno uvučen u granice vremena i prostora. "Onaj koji dela ne vidi daleko. On ide, guran događajima, a da dobro ne vidi cilj” (šire u: Fevr 2004).

Vrhovne vrednosti i norme u procesu njihova ostvarivanja bivaju iskrivljene i iskvarene dok stignu u blizinu svoga cilja. Ali sve vrste normi - običajne, verske, moralne, pravne itd. - štite čoveka od čoveka. Ako nemamo izgrađen sistem vrednosti i normi koje iz njih slede, onda obično imamo ad hoc mnjenja i stavove o ovome ili onome. O tim vrednostima i normama ne bi trebalo samo misliti nego po njima živeti. Mudrost svih ljudi može se svesti na poznavanje i ostvarivanje ovih vrednosti i normi. To je gotovo jednako definiciji čoveka. Moralne vrednosti i norme su dokaz da mi kao ljudi nismo samo prirodna nego i kulturna bića. Norme nisu tu da samo ograniče nego i da omoguće razvoj ljudskih bića.

Sloboda, pravda, istina, dobrota, solidarnost, dostojanstvo itd. jesu pojmovi u koje se više ne veruje. Ali veličina čoveka nije u tome da nikad moralno ne posrne, nego u tome da smogne novu snagu da se uspravi i ispravi. Postoje opšte ili univerzalne vrednosti i norme koje unose red u svet, koje mire i ujedinjuju ljude koji su razjedinjeni i izdeljeni. Ako se teži univerzalnom dobru, onda mora da se pita etika, jer ona govori o stvarima koje se tiču svih ljudi. Svaka kultura i svako vreme mora da se preispituje s obzirom na ove vrednosti i norme, kako bi se videlo da li su one još uvek putokazi, ili su možda potisnute, zaboravljene, napuštene. Treba sučeliti društvo sa njegovim vlastitim vrednostima i normama da bi se uvidelo koliko je ono skrenulo sa pravoga puta. Kada bi se država zaista pridržavala zakona koje je sama donela, ona bi morala da samu sebe uhapsi.

Čuvati i braniti univerzalne vrednosti i norme ne znači poricati lokalne vrednosti i lično iskustvo - ove tri ravni svakako se razlikuju, ali se ne isključuju. Jer iznad razlika koje nas dele, stoje zajedničke vrednosti i norme koje nas povezuju. Ako nema tih vrednosti i normi, onda nema ni više čovekove prirode - on se srozava u društveni mravinjak. Etika upućuje na duhovne visine na koje čovek može da se propne ako ne želi "da bude dirka na klaviru na kojem svira neko drugi”. Vreme u kome živimo jeste vreme anarhije vrednosti i normi. Zato se pod hitno mora postaviti neka vrednost i norma, ili celovit sistem vrednosti i normi, kao merilo, kako bi naše mišljenje, verovanje i ponašanje bilo jasno, zakonito i osmišljeno. Usvajanje univerzalnih vrednosti i 
normi dovodi do izgradnje takvog karaktera čoveka kada su u skladu njegove misli, reči i dela.

U etičkim normama čuva se ono što je u stvarnosti od značaja i značenja, što nije prolazno kao život vodenog cveta. Ljudi nisu svesni koliko je opasno brzopleto menjanje jednog vrednosno-normativnog sistema i njegovo zamenjivanje drugim, ili ulazak $u$ vrednosni haos i prazninu. Zato vrednosni sistem mora biti relativno stabilan, jer samo tako služi kao orijentir misli i činu, kao integrativno sredstvo, kao motivacioni činilac, kao znak identiteta i identifikacije, kao merilo smisla, kao brana protiv svakog zla. Svaki postupak vredi onoliko koliko doprinosi ostvarenju etičkih vrednosti: ima se jasno merilo za ocenjivanje! Norma govori šta treba da se čini, iskustvo šta se stvarno čini. Nema slobode bez granica slobode: valjana ograničenja čine ljude slobodnim! Nema toga političkog sistema, makar on bio i demokratski, koji može da opstane bez ikakvih ograničenja, to jest bez pridržavanja osnovnih moralnih načela i pravnih normi, pri čemu moral ima apsolutnu prednost pred pravom. Norma nešto zabranjuje, ali i mnogo toga omogućava. Danas se moralni ljudi mogu upisati u prosjačke redove.

Od moralnog čoveka se očekuje da moralno deluje, a ne samo da moralno rasuđuje: on je vidljivi primer moralne norme koja se kreće među ljudima. Savremenom čoveku nisu toliko potrebne moralne pouke koliko moralne osobe koje žive čestit život i koje ga svojim primerom navode da i on tako živi. Ne treba niko da ga uči, nego da svedoči svojim životom kako se veruje i nada, ljubi i strada. Moral je stvar volje, a ne znanja. Dobrog čoveka ne može da stvori etika, kao što ni vrsnog umetnika ne može da stvori estetika: potrebni su prirodni dar i moć stvaranja!

\title{
Religija i religijska ideologija
}

\author{
Kada u državi ima dosta razloga za mržnju, \\ religija mora da pruži mnogo načina za pomirenje. \\ Šarl Monteskje
}

Ako se uporede svetske religije, onda će se ustanoviti da u njihovim učenjima preovlađuju stavovi razumevanja, trpeljivosti, mira i ljubavi. Samo u 20. veku u Evropi je bilo preko 100 ratova. Između koga? Pa između hrišćanskih zemalja. A hrišćanstvo je religija ljubavi. Bog je ljubav. Deus caritas est. Ako je to tako, a jeste, otkuda onda nerazumevanje, netrpeljivost, sukobi i ratovi? Očigledno da ove pojave ne dolaze iz religije. Odakle onda dolaze? Dolaze iz religijske ideologije (klerikalizma, nacionalizma, fundamentaliz- 
ma) - kad se vera stavi u službu ograničenih interesa. Prema tome, svete reči osnivača svetskih religija ne sadrže ništa što bi ličilo na netrpeljivost, mržnju i rat. Ako bi rat zavisio od vere, onda rata ne bi ni bilo, jer su vere po pravilu vere u mir. Sve su vere usvojile zlatno pravilo: "Ne čini drugome ono što ne bi želeo da on tebi čini."

Ivan svih ovih godina upozorava na to da "sveti spisi daju uporište za nenasilje", da "religije nisu konfliktne", ali da se religija često zloupotrebljava u političke ciljeve. "Ako su pisani religijski izvori okrenuti k nenasilju, začuđujuće je otkud toliki broj vernika sklonih mržnji i nasilju? Zar to nije pokazala i tragedija naroda na prostorima eks. Jugoslavije posljednje decenije XX stoljeća? Gdje su korijeni tog nasilja? Očito u lažnom vjerskom identitetu" (Cvitković 2003: 16). ${ }^{2}$ Put za jačanje nenasilja je poznat. Hans King ističe: "Nema mira među narodima bez mira među religijama." Ivan zaključuje: "Važna je interpretacija religijskih učenja u skladu sa univerzalnim načelima u čijem središtu je slobodan život i ravnopravnost svih ljudi. Vraćanje religijskih zajednica njihovim vlastitim izvorima. Čini se da je bitno da religijski svjetonazor ostane, što je više moguće, izvan politike" (Cvitković 2003).

Religija je širi pojam od crkve, jer se verski život odvija i izvan crkve. Politika je širi pojam od države, jer se društveni život odvija i izvan državnih ustanova. U službenim čuvarima svetog, i u zvaničnim nosiocima moći, ljudi obožavaju mogućnost uređenog života, nasuprot silama nereda. Crkvena vlast je duhovna, državna vlast je politička: prva se odnosi na čovekovu dušu, druga na njegovo telo! Crkva nadahnjuje višu prirodu, država kroti nižu: duhovni poglavar i politički vladar trebalo bi da se uzajamno dopunjuju! Tada je nebeski red relativno saobražen sa zemaljskim poretkom. Ali ni oltar ni presto, ni crkva ni država nisu ostvarile vrednosti hrišćanske vere i humanističkog morala: nisu učinile boljim duše vernika i ponašanje podanika!

Temeljne vrednosti i norme svake svetske religije su iste. To su pravda, ljubav, mir. U Jevanđelju po Mateju stoji: “Sve što hoćete da vama čine ljudi tako činite i vi njima." U Talmudu, svetoj knjizi jevrejske vere, piše: "Ono što ti prezireš, nemoj učiniti svome susedu." Sveta knjiga islamske vere Kuran sadrži isto: "Niko od nas nije vernik ako bratu ne želi isto što i sebi." Kineski mudrac Konfučije (551-479. pr. n. e.) istakao je tzv. zlatno pravilo: "Ne čini drugima ono što ne želiš da oni urade tebi." Ovo zlatno pravilo oduvek je prisutno u ljudskom duhu, pa ga filozofi zovu "princip velike starosti". Ukratko: cela religijska kultura je - univerzalno izražavanje mira i ljubavi. Jezik ljubavi je maternji jezik svih svetskih religija. Zato Amin Maluf (2009) i može reći: "Ljubav je bolest od koje niko ne želi da se leči."

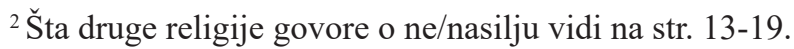


Dobro se sećam svetih reči iz Kurana: "Natječite se ko će više dobra učiniti... Naš bog i vaš bog jedan je bog." To su zapravo tri imena za jednog boga, u smislu da je reč o istom sistemu vrednosti (šire u: Kuschel 2003). Vernici se mole za red i mir u sebi i svetu, što znači da su netrpeljivost, mržnja i rat u opreci sa smislom vere. Zato Sv. Sava i reče: “Ako je pop grešan, molitva nije." A u Jevanđelju po Marku se ističe: "Dom moj zvaće se dom molitve za sve narode. A vi od njega načiniste hajdučku pećinu." Može li onda ideolog neke vere da govori u ime vere? Naravno da ne može, jer bi to bila vera protumačena u ideološkom ključu, s obzirom na interes pojedinca ili neke verske zajednice. Zato je neophodno da se napravi oštra razlika između vere i verske ideologije.

Svaki religiozni sistem vrednosti i normi stoji nasuprot nekom zlu: tako sistem vrednosti i normi prerasta u religiju spasenja! Ostvarivanje ovih vrednosti i normi gotovo da je jednako definiciji čoveka. Sve vrste kulturnih normi (verske, moralne, običajne, pravne i sl.) štite čoveka od čoveka, ali sa malo uspeha, jer 90\% ljudskog bića je iracionalno. A norma je racionalno pravilo i deluje na onih desetak posto racionalnog u čoveku. Primer: Nemačka je bila najobrazovanija i najracionalnija nacija u Evropi, a izazvala je dva svetska rata sa neviđenim zverstvima. Misliti o čoveku kao o racionalnom ili svesnom biću bez ovog iracionalnog ili nesvesnog, nije mudro. Zato ima onih koji misle da između pojmova religija i rat gotovo da nema razlike. "Narodi ne ratuju samo zbog zemlje, bogatstva i interesa; oni se bore i da bi druge primorali da svet sagledaju onako kao oni." Ništa nije vredno što se može novcem platiti. Nema jemstva da ćemo biti bolji ako nam je bolje - materijalno smo bogatiji, duhovno siromašniji. To se najočiglednije pokazuje u tumačenju istorije (šire u: Bruks 2012: 275).

Već u 5. stoleću Sv. Avgustin je pisao o pravednom ratu. Ali nema pravednog rata, jer u ratu stradaju nevini. Osim toga, svi ratovi potiru istine. Umesto isticanja pobeda i poraza valjalo bi gajiti zajedničko sećanje na uzaludne žrtve kao osnovu za buduće odnose. Nikolo Makijaveli veli: "Ko god želi da vidi ono što će biti, treba da razmotri ono što je bilo." Ne vidiš dobro ispred sebe ako ne gledaš iza sebe. "Budućnost ne bi trebalo da sadrži previše prošlosti” (Kurejši 2014: 172; 2017). Ko od prošlosti pravi svoju jedinu misao, svoju duhovnu kuću, taj je mrtav za sadašnjost i budućnost.

Ideološki jezik je zatvoren: ideologija je govor koji jedna grupa drži samoj sebi dajući za pravo svome interesu! Niče bi rekao: "Ideologija je koristan način pogrešnog tumačenja vere.” Ideologu nije stalo do istine, već do interesa: zato je on sklon da brani neistinit iskaz ako mu koristi i odbaci istinit ako mu šteti! Kad interesi viču, istina se ne može čuti. Još je V. Lenjin govorio: 
"Kad bi interesi ljudi zadirali u geometrijske aksiome, ljudi bi ih pobijali." Čovek je racionalno biće, a mnogo više biće koje racionalizuje. Istina ima svoje heroje, interesi svoje robove. Ideologija je gluma istine. Ideolog je čovek širokog osmeha i uskog pogleda na svet, ponosan na vlastitu ograničenost i time trajno udaljen od svojih neograničenih mogućnosti - udaljen od istine i samog sebe.

O ovome govori sledeća pričica. U Severnoj Irskoj, protestantski pastor, katolički sveštenik i jevrejski rabin upustili su se u oštru teološku raspravu. Anđeo, koji se spustio s neba, upita ih da izraze svoje želje u pravcu mira i ljubavi. Protestantski pastor je rekao: "Neka svi katolici nestanu s našeg lepog ostrva i zavladaće mir." Katolički sveštenik je rekao: "Kada i poslednji protestant ode s naše svete irske zemlje, na ostrvu će biti mir." "A ti rabi?", upitao je anđeo. "Imaš li neku želju?" "Nemam" - rekao je rabin. "Dovoljno je da se ispune želje ove velečasne gospode i biću zadovoljan” (Melo 2000: 43). U Prvom i Drugom svetskom ratu sve su crkve blagoslovile vojnike i njihovo oružje.

Ono što počinje kao čista ideja, završava kao prljava ideologija. Niče je primetio da sve ideje stižu u blizinu svoga cilja iskrivljene. Svaka velika religija počela je teološki mudro i završila ideološki glupo: braneći neki ograničeni interes! Ovo važi i za cele kulture. Kultura je proces stvaranja opštih značenja: jedni ih prave, drugi kvare, jer ih tumače uvek u skladu sa svojim interesima. Kada je krst postao simbol vojnih odreda, a ne samo verskih obreda, onda su sve pobede u ratu bile povezane i sa krstom, a ne samo sa mačem. Umesto ideje mira nastupa ideologija rata: krvava svađa braće u istome domu! Počeo je bratoubilački rat između braće čije su male razlike izazvale goleme posledice. To nije rat verski, nego rat zverski. Dostojevski je u pravu: “Zver ne može nikad da bude tako okrutna kao čovek, tako virtuozno, tako umetnički okrutna." Ubija se obredno. "Nasilje postaje razonoda" (Jursenar 2004: 78). Nestajala je razlika između simboličkog i stvarnog nasilja i silovanja. "Šta ćemo sa dugom, sumornom i strašnom istorijom hrišćanskog antisemitizma?" (Tejlor 2011: 719). "Dobro koje predstavlja naš cilj, našu viziju poretka, nekako iščezava kada počne borba za njegovu realizaciju" (Tejlor 2011). ${ }^{3}$

\footnotetext{
${ }^{3}$ Kako je bilo moguće da se vekovima osporavala teološka jednostavnost, filozofska dubina, moralna čistota, poetska svežina i duhovna suština islama? A islam je deo evropskog kulturnog identiteta. Vil Djurant u knjizi Doba vere (1998) ističe da je pet vekova (od 700 do 1200. godine) islam u svetu prednjačio u kulturnom pogledu. "Da, potrebno je ponajprije priznati doprinos islama i muslimana europskoj kulturi i tradiciji” (Cvitković 2016: 22).
} 
Ako je rat naša sudbina, onda svaki pokušaj da se rat izbegne izgleda uzaludan. Ako je rat stvar izbora, onda nam se otvara šire polje delovanja, kako bi rat nestao iz naše svesti i našeg sveta. Vreme ne isključuje nadu: naša istorija je otvorena! "Ne boj se, malo stado" (Luka 12: 32). Može li se nasilje razumeti u biološkim terminima, ili se moramo osloniti na metabiološko? Biološko je ono što delimo sa drugim životinjama. U područje metabiološkog se stupa kada se ima potreba za određenjem smisla (Tejlor 2011: 665). "Raščarani svet izgleda kao svet bez smisla" (Tejlor 2011: 688). "Ljubi bližnjega svoga kao samoga sebe" - to je načelo koje vredi, ali se ne slaže sa iskustvom. Nađite mi moralno načelo koje se slaže sa iskustvom. Pa zato i jeste načelo, jer je postavljeno nasuprot iskustvu, u želji da ga izmeni.

Ako je u svakoj velikoj verskoj tradiciji bilo proroka, mistika, svetaca i monaha, onda je u svakoj bilo protivnika rata, jer prorok, mistik, svetac i monah ne vode rat protiv drugih, nego ratuju sami sa sobom, protiv svojih grešaka i grehova. Svi oni nastoje da pobede zlo u sebi. Oni su bili čuvari mira i čuvari razlika, a ne zvanična crkva, džamija, sinagoga itd. koje su toliko puta pale u zagrljaj svetovnim bogovima. Zvanična vera na taj način narušava božanski, vaseljenski, ritualni, moralni i pravni poredak. Kada ljudi vode rat, onda i svoje bogove izvode na bojno polje, a oni su do tada mirno boravili u nebeskim visinama - na delu su zaruke mača i krsta, ikone i sekire. Nije vera samo jedna ugodna sveta priča kojom se zamagljuje jedna neugodna svetovna istina. "Svakako, svako doba u predanju ostavlja više traga o svom jadu nego o svojoj sreći. Bolne sudbine postaju istorija" (šire u: Hojzinga 1991). Srećni smo kad nas bar jedna nesreća mimoiđe. Ovde nema mira, ni pomirenja, može biti samo primirenja. I danas vredi stara šala o povremenom izbijanju mira - to je veran opis naše stvarnosti. Bolji je i nepravedan mir od pravednog rata. Onaj ko ratuje u ime vere čini zločin protiv vere.

Slobodan Jovanović je govorio da ljudi vode dve vrste borbe, jednu s prirodom, a drugu između sebe: prva borba se naziva rad, a druga rat (Jovanović 1990: 326). Rad stvara vrednosti, rat ih razara: rad stvara višak vrednosti, rat višak gluposti! Čovek je kadar da povede rat, ali nesposoban da sklopi trajan mir: mir se sklapa kada obe ili više strana iznemognu, jer ih neko treći primiri radi vlastite koristi. Tako je svaki mir samo predah između dva rata, $i$ opet tako, u beskraj. "Rat je praznik smrti: on prazni crkve i džamije, a puni groblja” (Cvitković 1996: 105). Neko, ne znam više ko, dobro reče: "Istorija, naime, nalikuje groblju ograničenog prostora, na kojem u svakom trenutku treba naći mesta za nove grobove." 
Šta onda znači priča o kraju istorije (F. Fukujama), ili kraju ideologije (D. Bel), to jest o kraju sukoba, ako ne nepoznavanje ljudske prirode. Sporovi, sukobi i ratovi upisani su u strukturu ljudskog bića i ispisani u njegovoj istoriji, koja je neoboriv pregled i prikaz tih borbi, toga nereda u životu. Ali bez nereda ne bi bilo promena, a bez reda ne bi bilo tradicije. "Ali rat je prilika za velike plemenite akcije, kao i za neopisive zločine i užase" (Tejlor 2011: 635). Psi rata povećavaju svoju ekonomsku i političku moć, ali sužavaju i poriču svoju čovečnost. Suprotnost između dobra i zla je apstraktna, borba između dobrih i zlih ljudi je konkretna. U svakom žitu ima kukolja, u svakom rodu izroda.

Ludaci su dospeli na vlast, zato i imamo stalne sporove, sukobe i ratove. Filozof volje za moć Fridrih Niče viče: "Došlo je vreme da se ponovo promisli šta je politika, jer onakva kakva je danas, ona je mesto gde su sve duševne bolesti zakazale sastanak." A davno pre njega, Blez Paskal je isticao: "Govoriti i pisati o politici, to je ravno pokušaju da se unese red u ludnicu." "Niko, naime, nije tako lud da pre izabere rat nego mir, jer u miru deca sahranjuju svoje očeve a u ratu očevi decu" (Arsenić 1988: 49). Johan Galtung uverljivo pokazuje i dokazuje da su podsvesne i nesvesne pretpostavke zapadne kulture pune prikrivenog nasilja: to je upravo dihotomno mišljenje (pobeda - poraz, $\mathrm{za}$ - protiv itd.) koje je u opreci sa jedinstvom sveta... Tu je ideja boga i đavola, što u političkom životu odgovara ideji prijatelj - neprijatelj (Galtung 2009: 108; v. i spise Karla Šmita).

\section{$* * *$}

Samo je bog savršen, a njegova deca to nisu. Zato moraju da rade na sebi da bi se usavršili. A to je moguće u razgovoru, u nežnom susretu razlika, u njihovom stalnom nadilaženju, bez kraja. To je i danas jedini vidljiv put za spasenje. Stvarni uslovi za razgovor istorijski su pripremljeni sa pojavom Hristovog učenja o ljubavi, jer nema razgovora među onima koji se mrze. U razgovoru se barem ništa ne ruši osim zabluda i laži. Bolje je bezuspešno razgovarati nego uspešno ratovati. Ulažu se ogromni napori da se prevaziđu spoljašnja ograničenja, ali ono što nam je još potrebnije, to su napori za prevladavanje unutrašnjih granica - palanke u nama. Stvaranje jedne zajednice, jedne ustanove, ili jedne kulture veoma je sporo i teško, ali njihovo razbijanje i uništenje brzo i lako. Neki ljudi marljivo rade i grade, da bi neki drugi imali šta da pogaze i poruše. I sam osećam da reči moje, kao ptice bez krila, u nemoći stoje. Samo nam dijalog preostaje kao tihi poziv do istine i mira. 


\section{Susret razlika i ne/trpeljivost}

Ako ste uhvaćeni u senku nekog drugog, sa vama je gotovo.

Drugi snivaju svoje snove kroz vas.

Žil Delez

Ivan Cvitković je istinski prijatelj pravde i prava. On dobro zna da je svakoj stranci istina strana, jer ona misli da je istina na njenoj strani. Sve stranke su daleko od istine. On je na strani istine. Oni što misle da je uz njih, jednako se varaju kao i onih koji veruju da je protiv njih, jer ne vide da je iznad njih. Ako se od njega očekuje da bude stručan i da se pridržava merila istine, onda ne može da podržava bilo čiju stranu. Ko ima svoje mišljenje (stečeno dugim iskustvom, naučnom metodom i odgovarajućom teorijom), odstupa od mišljenja svake stranke - i tako opet ima sve protiv sebe. Ako ne podržava nijednu stranu u sukobu, stran je svakoj, i smatraće ga strancem dok je živ. Ali u njegovoj misli ima istine i smisla u meri u kojoj ona nije mogla da posluži nijednoj stranci da je ispiše na svojoj borbenoj zastavi.

On odbija da golim rukama meša vatru i vodu, da jedne fanatike pomiri sa drugim fanaticima, da jednoj dogmi pruži ruku, a drugoj da okrene leđa. On je čovek sam za sebe, homo per se. Ali po pravilu, uvek je onaj ko nije u nekoj stranci važan za nju, osobito ako je ugledna i značajna ličnost. Ali njegovo vreme dolazi, uvek ponovo dolazi, kako ističe Štefan Cvajg pišući o Erazmu Roterdamskom, koji je stalno ostajao neutralan ili neopredeljen u borbi posebnih političkih interesa, štiteći opšti interes čovečanstva. Duh traži svoje moralno pravo pored prava jakih: umesto puške uzima knjigu u svoje ruke! "Slobodan kao svi usamljeni ljudi, i usamljen kao svi slobodni” (Cvajg 1983: 346, 337). "Sa one strane ideje o dobrim i lošim delima, postoji jedno polje. Tamo ćemo se naći”, mudro je slovio Dželaludin Rumi još u 13. veku naše ere.

Naravno, u kriznim vremenima, mnogo je teže ostati neutralan i neopredeljen nego aktivan i neopredeljen. To objašnjava zašto je i duh postao stranački. To je ulazak u duhovni mrak, u epohu mračnjaštva. Nevini narod ne dobija ništa, ni od pobede ni od poraza, on je po pravilu izigran u tim ratničkim igrama. Otuda dužnost humanistički orijentisanog sociologa-mislioca da svoju časnu reč poseje u jedan nečastan svet, da posredstvom duha obnovi čistiju čovečnost. Erih From ima pravo da kaže: "Povijest opravdava one koji govore istinu, a ne one koji vladaju... Oni su ljudska savest koja progovara kad svi šute" (v. Cvitković 2004). 
Ono što duhovni ljudi smatraju istorijski važnim uopšte ne dopire do svesti masa. Nova osećanja i kritička misao uvek su dohvatljivi i shvatljivi izabranoj manjini, odnosno eliti, ali ne i masi, kojoj se ta osećanja i te apstraktne, univerzalne, kosmopolitske i nadnacionalne ideje moraju oteloviti u obliku živa čoveka, jednom uzoru za sve druge, koji će ga oponašati i slediti. Ali širenje niže kulture išlo je na uštrb razvoja više kulture. Stupanje masa na političku pozornicu povezano je sa širenjem niže, masovne kulture. To je bio narodni čovek, čovek malog mozga i velikog srca, naivčina koga je svako mogao da prevari i iskoristi. To nije bio tip čoveka koji se posvećuje suštinskoj strani stvari, već kako nalažu hirovi ličnosti i raspoloženje trenutka. Ključna greška humanizma bila je u tome što je hteo da poučava narod sa visine, umesto da svoje učenje pokaže, prikaže i dokaže u obliku živa čoveka, koji je usvojio to učenje, koje ga vodi kroz život i oblikuje svet oko njega. Setimo se takvih ljudi - svetiljki u mraku: Sokrat, Hrist, Buda, Tolstoj, Gandi, Martin Luter King, nadbiskup Oskar Romero, patrijarh Pavle i desetine drugih koji su upozoravali na to da je nasilje poricanje svake vrednosti ljudskom biću. Temeljni nagoni ne mogu se odstraniti verskim i moralnim propovedima, pa se varvarstvo ne da ukinuti.

Ivan je celo vreme, za svog radnog veka i posle, govorio i pisao prave stvari, ali imam utisak da je, kao i svaki uman čovek, sam sebe čuo. Njegov životni poziv nalaže: ono što društveno nije moguće, valja duhovno hteti, jer se jedna zajednica duhovno oblikuje pre njenog stvarnog oblika. Trebalo bi očuvati u životu taj smisao za ono što ljudi mogu, hoće ili trebaju, nezavisno od toga da li je to trenutno, u datim okolnostima, ostvarivo. Nada je višak želje i slutnje, a manjak iskustva i znanja. Nadom se život hrani i brani od svakog zla. Migel de Unamuno, španski filozof, tražio je: "Pustite me da sanjam. Ako je taj san moj život, ne budite me." Postoji samo jedan duhovni spor, spor između smisla i besmisla. Koga ne zanima etika, toga ne zanima čovek. Nama je potrebna etika životne sredine, jer je zagađena kako prirodna tako i duhovna sredina. Ono što ostaje iza duhovnog čoveka može da neznatno produži njegov život biološki (potomci) i kulturološki (sledbenici). Živeće dok ima živih koji ga se sećaju.

Oni koji znaju ništa ne mogu, ovi koji mogu ništa ne znaju. I tako stojimo na mestu ili nazadujemo, iako imamo i znanja i moći. Zato danas gotovo sve možemo pisati malim slovom, jer je sve uniženo i umanjeno, a naročito duh. To nije neočekivano u narodu koji je oduvek bio više usmen nego pismen, više gladan nego sit. Nama svakako treba neko mudar i hrabar da nas izvuče iz ove kaljuže, ali mudar ne želi da se upliće u tuđe živote, kao što ne želi da se bilo ko upliće u njegov. Ni on nije siguran da bi ljudi bili dobri ako im je 
dobro. Verovatnije je da bi još jednom stradali nevini. Ivan Cvitković bio je svedok tog stradanja.

Dok sam čitao njegove brojne radove, uverio sam se da u svakoj svojoj knjizi, eseju, članku, osvrtu, prikazu itd. ističe potrebu za dijalogom i tolerancijom. Jer dijalog nije u službi nekog spoljašnjeg cilja, već u ulozi razvoja ličnosti: lepa ličnost i mudra misao rađaju se samo u razgovoru! Ko nije kadar da razgovara, taj nije sposoban za razvoj. Odustati od razgovora sa drugim znači odustati od sebe! Horhe Luis Borhes piše: "Dva čoveka, koji umeju da razgovaraju, mogu sebe neizmerno da obogate i razviju. Ono što dolazi iz mene ne iznenađuje me toliko koliko ono što primam od drugoga."

Najdublji razlog u prilog toleranciji leži u tome što bez nje ne bismo nikad mogli da upoznamo raznovrsnost iskustava, osećanja, misli, verovanja i delovanja pojedinaca i grupa. Dopustiti da se pojave sva mišljenja i sva uverenja nije toliko stvar tolerancije koliko razboritosti: to prosto obogaćuje našu misao i naš život! Voditi tolerantan razgovor o svakom pitanju znači ugrađivati lične i posebne interese u opšte dobro. Voditi trpeljiv razgovor znači stvarati zajednicu koja sama sobom upravlja i koja ne treba upravljača sa strane. Latinska reč tolerancija izvorno znači "trpeti, podnositi, popustiti, dopustiti, snositi". Ivan napušta to etimološko značenje 4 i umesto njega predlaže razvijanje kulture susreta: nositi drugog u sebi (a ne podnositi ga, trpeti ga), sebe prepoznati u njemu (jer su njegova pitanja i moja), "saviti gnezdo u tuđoj duši”, poštovati i uvažavati drugog i drukčijeg zbog njega i zbog sebe. Drugim rečima, valja priznati razlike, upoznati razlike, prihvatiti razlike, radovati se razlikama (jer nas obogaćuju). Mi živimo sa razlikama i živećemo dok smo živi.

Tolerancija je stav ukoliko se odnosi na mišljenje drugog, a čin ukoliko se odnosi na ponašanje ili postupke drugog: tolerancija nema granica što se tiče mišljenja, ali ima granice kad je reč o ponašanju ili postupku. Ne bi trebalo biti tolerantan prema nekome ko ugrožava druge. Biti tolerantan prema njemu znači i sam učestvovati u zlu! Drugim rečima, trebalo bi omogućiti da se izraze sva moguća mišljenja, a onda u razboritoj raspravi pokazati i dokazati netrpeljivima da su im misli jednostrane, pogrešne i da vode u neprilike. Ako se oni ne mogu razuveriti u slobodnoj raspravi, već hoće da deluju na pogrešnim pretpostavkama, zajednica ima pravo da ih u tome spreči, kako bi kasnije izbegla teže posledice. U tom trenutku trpeljivost zajednice polaže ispit zrelosti s obzirom na sutrašnji dan života. Tako je, na primer, u satirama grčkih pisaca bilo dozvoljeno ruganje ne samo Sokratu, koji je za glavu bio viši od

\footnotetext{
4 "No, iziđimo iz tolerancije i pođimo k susretanjima. Tolerancija vodi životu jednih pored drugih, susretanja životu s drugima” (Cvitković 2016: 32).
} 
Atine, nego i bogovima, ali se niko nije usudio da ometa obredne radnje ili da ruši kipove božanstava.

Prema tome, osnovni pokazatelji moje trpeljivosti su dvostruki: teorijski i praktični. Moja trpeljivost ne znači da ću bez pogovora prihvatiti i složiti se sa činjenicom da iskrivljeno ili lažno tumačiš činjenice. Moja trpeljivost podrazumeva razumevanje i čovečan odnos prema tebi, koji si, možda, bez svoje zasluge i krivice, usvojio iskrivljene, neistinite i lažne ideje, verovanja i vrednosti. Ja ću, dakle, biti nemilosrdan kada je u pitanju kritika ili odbacivanje tvojih stavova, ali ću biti milostiv kada si u pitanju ti, jer mi ne pada na pamet da te bilo kako kaznim. Jovan Zlatousti veli: "Ja ne progonim jeretike, nego jeres." Uzdržavanje od osude na osnovu dobro obrazloženog suda jeste ono bitno u mojoj trpeljivosti prema tebi: odbacujući tvoje zablude, ja ne odbacujem tebe, svoga brata (sestru). Netrpeljiv sam prema laži, obziran sam prema lažovu. Ako bih bio trpeljiv prema tvojim lažima, onda i sam pristajem na laž: moja trpeljivost bila bi odustajanje od istine! Nema nagodbe sa lažovima: valja ostati ispravan i uspravan kao istina!

Postoji jedna veoma raširena i loša duhovna navika koja se uporno održava u načinu na koji mislimo i delujemo: da jednu misao, čim se pokaže neispravnom, odmah zamenimo njoj suprotnom, ne videći da i ova može biti pogrešna. Možda je teza-antiteza oblik mišljenja koji proizvodi stalan sukob sa drugim. Svet je mnogo složeniji od ove proste opreke, i dok to ne shvati, uvek će biti otvoren za proste i prostačke sporove i sukobe. Kada se zajednica cepa na dve stranke koje zastupaju suprotna ili isključiva mišljenja i ubeđenja, onda rascep ide kroz svakog pojedinca: duša se svakog lomi na dva dela! Ovde valja da se napusti formalno-logičko mišljenje u ime jednog dijaloškog i svestranijeg, jer dvovrednosna logika uprošćava misao i život, pošto je i u mišljenju i u životu po pravilu reč o stepenima, a ne logičkim krajnostima: ili se prikloni ili se ukloni! Te binarne podele, to svođenje brojnih mogućnosti izbora na dve, na crno i belo, to je nešto vrlo opasno, iako se čini logično. Hulio Kortasar dobro reče: "Između za i protiv koliko je možda." U ime ovoga možda Ivan osporava krajnosti bar na tri načina: otkriva nedoslednost u dokazima, pronalazi drukčije primere koje potvrđuju istraživanja, uklapa ih u širi teorijski i istorijski kontekst.

Ivan Cvitković, vrsni sociolog religije, ne zaboravlja da naglasi: "Početkom ovog stoljeća u Europskoj zajednici živi više od 20 milijuna muslimana... Islam je često religija prvih susjeda, u mnogim europskim državama u kojima kršćani čine većinu, to je druga religija po brojnosti sljedbenika... Muslimani i kršćani danas čine više od $1 \frac{1}{2}$ svjetskog stanovništva. Od njihovih odnosa, od odnosa unutar tih grupacija, a još više između njih, umnogome 
može ovisiti i mir u svijetu" (Cvitković 2011: 7-9). Upravo zato "savremeni intelektualac neće razmišljati o uspostavi ni kršćanske ni islamske države, njega zanima pravedna država, vladavina prava" (Cvitković 2011: 58). Ivan nastavlja: "I kršćanima i muslimanima potrebno je čišćenje pamćenja." Zaključak ne može biti jasniji i bolji: "Zar nije i muslimanima i kršćanima dosta 'bitaka protiv' i zar ih ne treba zamijeniti dijalogom sa svima" (Cvitković 2011: 154, 275). To je put koji, po rečima Hansa Kinga, vodi od ignorancije preko arogancije do tolerancije.

Ako se na ovim našim prostorima sve događa u krajnostima, onda je i mišljenje u krajnostima posve uobičajena stvar. Kao posledica podela i pripadnosti različitim i suprotnim stanama i strankama, nestalo je zajedničkog polja razumevanja. Čak je jezik tako strašno osakaćen da ne omogućava usaglašenost i razumevanje. Filozof volje za moć Fridrih Niče davno je upozorio: "Vrednost svih bolesnih stanja sastoji se u tome što ona pokazuju stanja koja su normalna, ali bi se teško videla u normalnim prilikama." U nas je niz pokolenja odraslo i dozrelo u autoritarnoj političkoj kulturi, pa je zato teško očekivati da se one brzo preusmere na demokratski način mišljenja, verovanja i ponašanja, jer je reč o posve drugoj lestvici vrednosti i normi. Pojedinac čiji je duh zarobljen ili okovan pojmovima svoga roda, plemena, nacije, rase, klase, vere, stranke itd. dokazuje da nije kadar da misli i deluje na način čoveka: njemu nedostaje ona rasudna moć i mogućnost uzdizanja do šireg gledišta i osećanja za univerzalne istine i vrednosti. On se još nije otvorio za više oblike mišljenja i življenja. Jer na univerzalnim značenjima počiva mogućnost ljudske zajednice, na posebnim se razvija grupa. Svi ti pozivi na pleme, naciju, rasu, klasu i sl. svedoče o tome da se taj pojedinac još nije razvio do građanskog načina osećanja, mišljenja i delanja, još nije postao ličnost. Rodovskoplemenska-nacionalna svest i način života na ovim prostorima teško se može uzdići na ravan univerzalnih vrednosti, normi i pravila ponašanja. Ovde je reč o sukobu opšteg načela tolerancije i posebne tradicije autoritarnog duha. Ako hrišćanstvo i islam kao univerzalne religije nisu uspele da za toliko vekova iskorene ovaj u suštini paganski način mišljenja i delanja, onda se ni mi danas ne možemo nadati da ćemo u bliskoj budućnosti imati više uspeha. Ivan bi, u svom stilu, verovatno rekao da smo još pogani, a ne samo pagani.

$$
* * *
$$

Ivan Cvitković, mudar i osetljiv na neki tihi način, neupadljiv i nenametljiv, kreće se po onoj tankoj niti koja deli široko polje nauka o čoveku, pokazujući i dokazujući da su one formalno odvojene, ali stvarno spadaju u istu priču: granica je ono čudno mesto koje razdvaja i spaja u isti čas! Već sam 
napomenuo da je malo ko u "vunenim vremenima" pridavao značaja onome što je on govorio i pisao, ali se kasnije pokazalo da je on bio u pravu, a da pravo, koje je formalno važilo, nije vredelo pišljiva boba. Bio je stranac među svojima, da istina ne bi ostala bez svedoka. To ponižavanje pameti išlo je dotle da je samo u nas moglo biti da tri univerziteta u jednoj državi nose imena jednog propalog đaka, jednog seoskog kovača i jednog partijskog aparatčika. Ivan je dugo vremena radio i pisao u prilikama koje nikom ne bi poželeo i uslovima kojima nikog ne bi kaznio: rukom na papiru i sa strepnjom da započeto neće biti dovršeno! Bio je brat svima koji stradaju i koji se nadaju. Blizak svakome po patnji koju ni sam nije izbegao, daleko od mnogih po svom stavu prema njoj: nije dopuštao da patnja prekine svaki savez sa nadom u sutrašnji dan! Činio je dobro i dobrima i lošim ljudima: čovek vredi onoliko koliko ljubavi za druge ima u sebi! Nalazio je čiste odgovore u mutnom i smutnom vremenu. Ne mogu da odolim iskušenju da on zaslužuje ime Ivan dobri.

\section{Literatura}

Arsenić, Milan (prev.) (1988), Herodotova istorija, knj. 1, Matica srpska, Novi Sad.

Bruks, Danijel (2012), Društvena životinja, Laguna, Beograd.

Cvajg, Štefan (1983), Erazmo Roterdamski, Rad, Beograd.

Cvitković, Ivan (1996), Sociologija religije, Edicija Univerzitetska knjiga, Ministarstvo obrazovanja, nauke, kulture i sporta, Sarajevo.

Cvitković, Ivan (1999), Religije suvremenoga svijeta, Fakultet političkih nauka / Svjetska konferencija religija za mir, Sarajevo.

Cvitković, Ivan (2003), Religija i (ne)nasilje. U: Milan Vukomanović - Marinko Vučinić (ur.) Religijski dijalog: drama razumevanja, Beogradska otvorena škola, Beograd, str. 11-20.

Cvitković, Ivan (2004), Konfesija u ratu, Interreligijska služba "Oči u oči" / Svjetlo riječi, Sarajevo / Zagreb.

Cvitković, Ivan (2005), Rječnik religijskih pojmova, 2. dopunjeno i prošireno izd., DES, Sarajevo.

Cvitković, Ivan (2011), Moj susjed musliman, Školska knjiga, Zagreb.

Cvitković, Ivan (2016), Religija u zrcalu teorija, Centar za empirijsko istraživanje religije CEIR, Sarajevo.

Djurant, Vil (1998), Doba vere, Narodna knjiga / Alfa, Beograd.

Fevr, Lisjen (2004), Borba za istoriju, Srpska književna zadruga, Beograd.

Flenegal, Ričard (2005), Guldova knjiga o ribi, Narodna knjiga - Alfa, Beograd.

Galtung, Johan (2009), Mirnim sredstvima do mira: Mir i sukob, razvoj i civilizacija, Službeni glasnik / Jugoistok XXI - Centar za evro-balkansku saradnju, Beograd.

Hamilton, Malkom (2003), Sociologija religije, Clio, Beograd.

Hojzinga, Johan (1991), Jesen srednjega veka, Matica srpska, Novi Sad.

Jovanović, Slobodan (1990), Sabrana dela, tom 10, BIGZ, Beograd.

Jursenar, Margerit (2004), Sirom otvorenih očiju, Politika / Narodna knjiga, Beograd.

Kolakovski, Lešek (1992), Užas metafizike, BIGZ, Beograd. 
Kurejši, Hanif (2014), Poslednja reč, Booka, Beograd.

Kurejši, Hanif (2017), Ništarija, Booka, Beograd.

Kuschel, Karl-Josef (2003), Od sporenja k natjecanju religija: Lessing i izazov islama,

Knjižnica Pravda i mir, knj. 7, Svjetlo riječi, Sarajevo / Zagreb.

Maluf, Amin (2009), Poremećenost sveta, Laguna, Beograd.

Melo, Antoni de (2000), Od molitve do prosvetljenja, L.O.M., Beograd.

Tejlor, Čarls (2011), Doba sekularizacije, Službeni glasnik, Beograd.

Valeri, Pol (2010), Sveske, Službeni glasnik, Beograd. 